\title{
Commentary: Not only SMART clinically, but translationally!
}

\author{
Harvey I. Pass, MD
}

\footnotetext{
From Division of General Thoracic Surgery, Department of Cardiothoracic Surgery, NYU Langone Medical Center, New York, NY.

Disclosures: Author has nothing to disclose with regard to commercial support.

Received for publication Sept 15, 2019; revisions received Sept 15, 2019; accepted for publication Sept 18, 2019; available ahead of print Oct 31, 2019.

Address for reprints: Harvey I. Pass, MD, NYU Langone Medical Center, 530 First Ave, 9V, New York, NY 10016 (E-mail: Harvey.Pass@nyumc.org).

J Thorac Cardiovasc Surg 2020;159:2094-5

$0022-5223 / \$ 36.00$

Copyright (c) 2019 by The American Association for Thoracic Surgery

https://doi.org/10.1016/j.jtcvs.2019.09.101
} enal results in non-small cell lung cancer when immunotherapy is combined with chemotherapy. ${ }^{1}$ These effects occur at the level of the tumor microenvironment, heterogeneously populated with $\mathrm{T}$ cells, dendritic cells, macrophages, as well as granulocytes. Checkpoint inhibition will "take the brakes off" of the inhibitory effect of immune cytotoxicity by modulating the PD-L1/PD-1 axis; however, studies have shown that you can get more "bang for your buck" when you add other therapies to the checkpoint inhibitors.

Early studies reveal that the chance for greater than $90 \%$ tumor kill, as well as long-term progression-free survivals and overall survivals, ${ }^{2}$ increase remarkably with combination therapy. Most recently, a taste of these encouraging results has been reported by Nowak and colleagues ${ }^{3}$ for mesothelioma, with a doubling of response rates compared with single-agent CPI inhibitors. Underlying all of these attempts at combination therapy is the strategy to increase tumor immunogenicity either by the release of deathassociated molecular patterns (ie, DAMPS or alarmins), promotion of anti-tumor CD8 $+\mathrm{T}$ cells, inhibition of myeloid-derived stem cell activity, or the increase of antigen expression. ${ }^{4}$

de Perrot and colleagues ${ }^{5}$ have led the way with the innovative use of preoperative radiation therapy followed by extrapleural pneumonectomy in mesothelioma with promising overall survival even in patients with lymph node involvement. Their present investigation of the effects of this therapy on the malignant pleural mesothelioma tumor microenvironment ${ }^{6}$ is a natural evolution of their in vivo work documenting a specific immune activation against the tumor associated with significant upregulation of CD8 $+\mathrm{T}$ cells of preoperative nonablative hypofractionated radiation. ${ }^{7}$ Obviously, an eventual goal would be the combination of checkpoint inhibition or some other immunotherapy with the SMART protocol to enhance tumor responses, but the approach of de Perrot
All thoracic surgeons by this time are aware of the phenom-

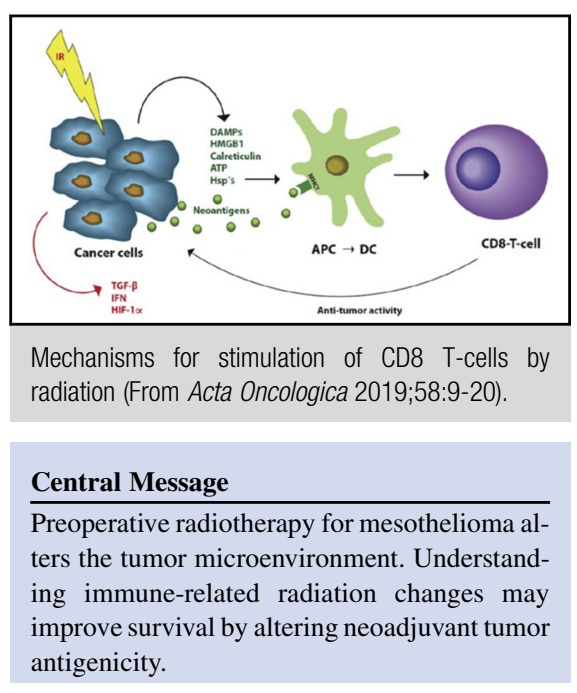

See Article page 2082. and colleagues is to be congratulated, since theirs is the first study in human mesothelioma to study baseline effects of hypofractionated radiation without the influence of other neoadjuvants.

It is unfortunate that we do not have the original biopsy specimen to interrogate and compare with the SMART specimens harvested at the time of surgery, and this is planned for the next series of studies. Yet, there are valuable take-home points to be studied and validated in the future, including the variability of prognosis depending on the levels of CD8-Til, PD-L1, and PD-1, as well as variability of effects depending on the malignant pleural mesothelioma histology. Future studies must tell us what the phenotype and function of these CD8 Tils are and why they are "decreased" after radiation therapy, as well as whether other factors in the interferon gamma pathway, including IRF1 and IRF2, could explain the increase in PD-L1 and better survival in epithelioid tumors. ${ }^{8,9}$

Finally, there are important T-cell receptor assays that could be performed on the tumors pre- and posttreatment, which can define the richness and clonality of T-cell receptor neoantigens, as described by Reuben and colleagues ${ }^{10}$ in the NEOSTAR study. These translational studies will be supplemented in the future by such techniques as singlecell RNAseq and digital spatial profiling of the microenvironment. When combined with mechanistic studies that detail the function of T-cell phenotypes, immunotherapists 
as well as surgeons will certainly be able to personalize and improve our therapies for pleural mesothelioma.

\section{References}

1. Gandhi L, Rodriguez-Abreu D, Gadgeel S, Esteban E, Felip E, De Angelis F, et al. Pembrolizumab plus chemotherapy in metastatic non-small-cell lung cancer. $N$ Engl J Med. 2018;378:2078-92.

2. Provencio MN, Insa E, Insa A, Garcia Campelo R, Casal J, Domine M, et al. NADIM Study: updated clinical research and outcomes. Presented at: WCLC 2019; September 2019; Barcelona, Spain.

3. Nowak A. DREAM: a phase 2 trial of DuRvalumab with First-Line chEmotherApy in mesothelioma with a safety lead-in. Presented at: International Mesothelioma Interest Group; Ottawa, Canada, 2018.

4. Joshi S, Durden DL. Combinatorial approach to improve cancer immunotherapy: rational drug design strategy to simultaneously hit multiple targets to kill tumor cells and to activate the immune system. J Oncol. 2019;2019:5245034.

5. de Perrot M, Feld R, Leighl NB, Hope A, Waddell TK, Keshavjee S, et al. Accelerated hemithoracic radiation followed by extrapleural pneumonectomy for malignant pleural mesothelioma. J Thorac Cardiovasc Surg. 2016;151: 468-73.

6. de Perrot M, Wu L, Cabanero M, et al. Prognostic impact of tumor microenvironment after hypofractionated radiation and surgery for mesothelioma. $J$ Thorac Cardiovasc Surg. 2020;159:2082-91.e1.

7. De La Maza L, Wu M, Wu L, Yun H, Zhao Y, Cattral M, et al. In situ vaccination after accelerated hypofractionated radiation and surgery in a mesothelioma mouse model. Clin Cancer Res. 2017;23:5502-13.

8. Shao L, Hou W, Scharping NE, Vendetti FP, Srivastava R, Roy CN, et al. IRF1 inhibits antitumor immunity through the upregulation of PD-L1 in the tumor cell. Cancer Immunol Res. 2019;7:1258-66.

9. Kriegsman BA, Vangala P, Chen BJ, Meraner P, Brass AL, Garber M, et al. Frequent loss of IRF2 in cancers leads to immune evasion through decreased MHC class I antigen presentation and increased pd-11 expression. J Immunol. 2019;203:1999-2010.

10. Reuben A, Zhang J, Lin H, Little L, Gumbs C, Tran HT, et al. T cell repertoire analysis of non-small cell lung cancer patients treated with neoadjuvant nivolumab alone or in combination with ipilimumab (NEOSTAR trial). Presented at: American Society for Clinical Oncology; Chicago, IL; 2019. 